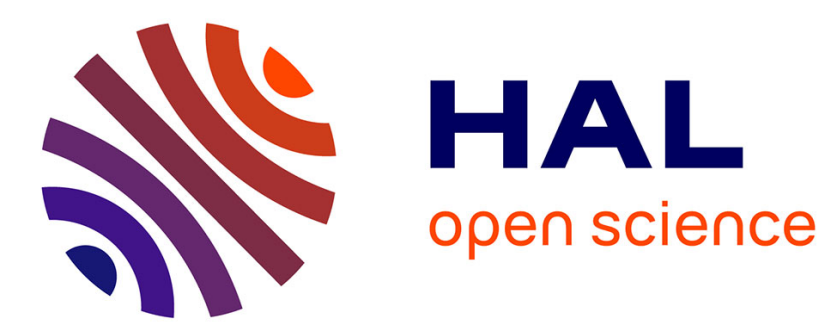

\title{
A Typology of the Unintended Consequences of Drug Crop Reduction \\ Pierre-Arnaud Chouvy
}

\section{To cite this version:}

Pierre-Arnaud Chouvy. A Typology of the Unintended Consequences of Drug Crop Reduction. Journal of Drug Issues, 2013, 43 (2), p. 216-130. 10.1177/0022042612467009 . hal-01048582

\section{HAL Id: hal-01048582 \\ https://hal.science/hal-01048582}

Submitted on 25 Jul 2014

HAL is a multi-disciplinary open access archive for the deposit and dissemination of scientific research documents, whether they are published or not. The documents may come from teaching and research institutions in France or abroad, or from public or private research centers.
L'archive ouverte pluridisciplinaire HAL, est destinée au dépôt et à la diffusion de documents scientifiques de niveau recherche, publiés ou non, émanant des établissements d'enseignement et de recherche français ou étrangers, des laboratoires publics ou privés. 


\title{
A Typology of the Unintended Consequences of Drug Crop Reduction (1)
}

\author{
Pierre-Arnaud Chouvy (2) \\ $* * *$ \\ First published in the Journal of Drug Issues on December 11, 2012 as doi:10.1177/0022042612467009 \\ $* * *$ \\ "People know what they do; frequently they know why they do what they do; \\ but what they don't know is what what they do does." \\ Michel Foucault, Madness and Civilization: A History of Insanity in the Age of Reason, 2006.
}

\begin{abstract}
:
Drug control policies and interventions, like any other policies and interventions, generate many unintended consequences. Most often, such consequences are mentioned without being defined or presented in a typology and they are rarely explained in terms of causality. This paper will stress how the existing work on the unintended consequences of drug control policies and interventions suffers from little or no definition and will then provide such a definition and a typology applied to three major interventions meant to achieve drug crop reduction: forced eradication, alternative development, and opium bans. In the end it will explain how a typology of unintended consequences can help to better understand the failure and even the counterproductivity of some interventions. Differentiating between direct and collateral unintended consequences allows us to better attribute the occurring of unintended consequences to a specific intervention and, or, to the intended consequence of the interventions.
\end{abstract}

The steady increase in global illegal opium production observed since the early 1970s (3) occurred in spite of the many efforts deployed by the international community to suppress or reduce illegal opium poppy cultivation worldwide. Illegal opium production has increased despite countless forced eradication campaigns and in spite of many crop substitution and alternative development programs. 
It can even be argued that the increase of illegal opium production is partly due, among other obvious push and pull actors, to the counterproductivity of forced eradication campaigns and to the inadequacy of alternative development projects. In fact it is now widely agreed that the global prohibition of certain drugs and the war on drugs have largely failed to reach their stated goals, that is, a drug-free world (Chouvy, 2009) (4).

Drug control policies and interventions, like other policies and interventions, generate many unintended consequences, most of which can be held responsible for the overall failure of prohibition (which can also be blamed for generating seriously disruptive unintended consequences) but also for countless collateral damages in the social, economic, political, environmental, and human rights areas. Alleged unintended consequences of drug control policies and interventions include crop displacement (one aspect of the so-called balloon effect), increased prices and production, worsened corruption, heightened armed violence (especially in the context of armed conflicts), weakened counterinsurgency, but also social unrest, ethnic insurgency, environmental degradation, increased deforestation, destruction of legal crops, increased poverty and debt, school dropouts, prostitution, human smuggling and trafficking, needle sharing and spread of blood-borne diseases, health issues from poor quality of drugs, substance switch, increased street crime and violence, deteriorated human rights, etc. (Bertram et al., 1996; Chouvy, 2009; Costa, 2008; Friesendorf, 2007; Heilmann, 2010 ; Nadelmann, 2010; Reuter, 2009; Tullis, 1995; World Bank, 2004; etc.).

Most often, such unintended consequences are mentioned without being defined or presented in a typology. They are also rarely explained in terms of causality, which is highly problematic considering how often drug control policies and interventions focus on consequences rather than on causes (for example targeting opium production instead of poverty and food insecurity) and how easily consequences can turn into causes of further consequences. It is also a problem because most such unintended consequences are the subject of highly controversial and passionate debates, for example, between advocates and opponents of forced eradication. A typology of unintended consequences of drug control policies and interventions is therefore needed not only to better understand the chains of causality that may hinder these policies and interventions, but also to help foresee and prevent the 
unintended consequences they might generate, especially the most perverse and harmful ones. This is basically what Ethan Nadelmann called for in a 2010 testimony to the U.S. congress on the war on drugs when he asked that "federal agencies involved in the drug war devote a portion of their budgets to evaluating the efficacy and unintended consequences of their policies and programs" (Nadelmann, 2010). A better understanding of unintended consequences is obviously a prerequisite to a better policy evaluation and, eventually, to better drug control policies: determining if a policy's consequences are intended or not, beneficial or harmful, or even perverse, is crucial.

This article will first stress how the existing work on the unintended consequences of drug control policies and interventions suffers from little or no definition. It will then provide such a definition. A typology of the unintended consequences of drug control policies and interventions will follow and will be applied to three major interventions meant to achieve drug crop reduction: forced eradication, alternative development, and opium bans (coercion not to plant). In the end it will explain how a typology of unintended consequences can help better understand the failure and even the counterproductivity of some interventions.

\section{Undefined unintended consequences}

In order to assess what the unintended consequences of drug control policies and interventions are, one first needs to define what unintended consequences are and, before that, assess what the stated goals of drug control policies are. According the 1961 Single Convention on Narcotic Drugs, the stated goal of the international drug control regime is to regulate the legal production, trade and consumption of drugs on the one hand and, on the other hand, to achieve the suppression of illegal drug production, trafficking and possession mainly through criminal law, that is, through prohibition measures. Yet, as many have observed, "the system, being a prohibition regime focusing on control of the production of psychoactive substances that are deemed to be harmful, has over time developed side-effects that were not foreseen (at least in their magnitude) when it was established" (Heilmann, 2010: 32). These side-effects, or unintended consequences, have been denounced at length for decades.

Yet, among the vast literature on drug issues very little material explains clearly what unintended consequences are and how they occur. LaMond Tullis' 1995 book on "Unintended Consequences. 
Illegal Drugs and Drug Policies in Nine Countries", for example, provides no definition or typology of unintended consequences. Other texts, such as a 1988 article by Ethan Nadelmann, describe unintended consequences in more details and even give a sense of the complexity of the issue but fall short of defining them (Nadelmann, 1988). Among the few authors that have attempted to define what unintended consequences are and how the concept applies to the field of illegal drug studies is Peter Reuter. In a 2009 exploratory report titled "The unintended consequences of drug policies", Reuter does not define what unintended consequences are but he raises a fundamental point when he explains that "an important distinction is between consequences that arise from prohibition itself, as opposed to those resulting from specific implementing programmes" (Reuters, 2009: 4). He then offers a valuable typology - which he terms taxonomy (5) - of unintended consequences, in which he details the mechanisms at work, the bearers of consequences, and the nature of harms (Reuter, 2009: 10). In the end, Reuter stresses a point of great importance when he writes that "almost all of the unintended consequences share one important characteristic; they are unmeasured" (Reuter, 2009: 10).

Indeed, most of the so-called unintended consequences of the illegal drug industry or of drug control policies and interventions are unmeasured and unproven, something that is explained in part because "measuring the illegal drug industry raises innumerable conceptual, technical, and political issues" (Thoumi, 2005: 186; see also Reuter \& Greenfield, 2001). In a text on unintended consequences, Antonio Maria Costa, a former Executive Director of the United Nations Office on Drugs and Crime, raises the case of such a consequence that is very often mentioned but never measured, the so-called balloon effect, or geographical displacement of a crop (Costa, 2008: 10). Costa rightly explains that large such balloon effects can be inferred from various repeated correlations but that the causality between a squeeze in one place and a swell in another place can hardly be measured or proven. Correlation obviously does not necessarily imply causation, something that the Fundamental Problem of Causal Inference - according to which it is impossible to observe the effect that would have happened if the determinant were exposed to another condition at the same time - only makes more complicated (Holland, 1986; Heckman, 2005). This is actually what Cornelius Friesendorf, the author of the most detailed and serious study of the balloon effect (a term 
he rightly rejects), stresses when he writes that "a heuristic, interpretative approach" is needed in order to grasp "the presence of various empirical black boxes, the presence of complex, dynamic interaction effects, the fuzzy nature of corruption and other phenomena contributing to displacement, and the difficulty of assigning causal weight to explanatory factors and processes" (Friesendorf, 2005: $67)$.

In his paper Costa lists five unintended consequences of what he terms "the control system and its application", that is, the prohibition regime on one hand, and drug control policies and interventions on the other hand, two very different things that he groups indiscriminately. The first unintended consequence he mentions, a "huge criminal black market", is clearly a consequence of the prohibition regime. The second unintended consequence is actually a consequence of the black market itself: what he calls the "policy displacement", that is, the focus on coercion and the allocation of public funds to law enforcement and public security rather than to public health. Geographical displacement, the third unintended consequence, is not a direct consequence of the prohibition regime but rather of drug production reduction interventions, especially bans and eradication. A fourth unintended consequence is "substance displacement", for example from opium to heroin: again, a consequence of repression, both at the production reduction and demand reduction levels. The fifth unintended consequence, according to Costa, is the exclusion and stigmatization of drug users, the causes of which are more difficult to ascertain. These unintended consequences, far from being exhaustive, differ at least according to their direct causes and, for the sake of clarity, should not be combined in a unique category. Where Costa is right, though, is when he writes that "unless we face these unintended consequences head-on, we will continue to be mesmerized by the many paradoxes of the drug problem" (Costa, 2008: 10-11). But before being faced head-on, unintended consequences first need to be defined and categorized according to their occurrence mechanisms and their causes. This is obviously no small task as Francisco Linares explains that, despite unintended consequences being "undoubtedly one of the key concepts in sociology" and despite the efforts of many scholars who have attempted its analysis (including Baert, Boudon, Elster, Merton, and Portes), "there is not a general explanatory model of the emergence of unintended consequences of social action" (Linares, 2009: 1). 
This essay obviously does not intend to offer such a general explanation. It is an initial attempt at better understanding the unintended consequences of drug control policies and interventions.

\section{Toward a definition and a typology of unintended consequences}

Strictly speaking, unintended consequences are consequences that were not planned for in a plan of action, whether the consequences are contrary or not to the actor's initial objectives. Of course, and as stressed by Daniel Little, an unintended consequence differs from an "unfortunate event" (6). In what is widely considered to be the seminal paper on unintended consequences, "The Unanticipated Consequences of Purposive Social Action" (1936), Robert Merton explained that, "rigorously speaking, the consequences of purposive action are limited to those elements in the resulting situation which are exclusively the outcome of the action, i.e., those elements which would not have occurred had the action not taken place" (Merton, 1936: 895). The unintended consequences of drug control policies should therefore be considered to be the direct and strict outcomes of drug control policies and interventions, that is, of the efforts produced to achieve the reduction or suppression of drug production, trafficking, and consumption.

Yet, Merton actually refers to unforeseen or unanticipated consequences in his paper, not to unintended consequences. He explains that "unforeseen consequences should not be identified with consequences which are necessarily undesirable (from the point of view of the actor)" and that the "intended and anticipated outcomes of purposive action, however, are always, in the nature of the case, relatively desirable to the actor, though they may seem axiologically negative to an outside observer" (Merton, 1936: 895). In fact, unintended consequences differ from unanticipated consequences (7) since outcomes that were not intended by purposive action can be foreseen or not: unintended consequences can be anticipated or not. Indeed, as Paul Helm explains, "a person might therefore not intend a particular consequence of his action but still foresee it. In saying that he might not intend a particular consequence it is implied not that the consequence is necessarily not intended but that it is neither intended nor unintended" (Helm, 1971: 51-52).

Moreover, an unintended consequence, whether foreseen or not, can also be harmful or beneficial, Adam Smith's "invisible hand" being a famous example of the latter. It can also be neutral but we will 
not concern ourselves with this specific case here. Daniel Little stresses that "we can't know all the possible results of an action undertaken". He then explains that the so-called law of unintended consequences implies that, "no matter how careful one is in estimating the probable consequences of a line of action, there is the residual possibility that the action will produce harmful unanticipated consequences that negate the purpose of the action" (what we will later call perverse unintended consequences). According to Little, the planner of an action "should design the plan so as to minimize avoidable bad consequences; then do a cost-benefit analysis to assess whether the value of the intended consequences outweighs the harms associated with the unintended consequences." Indeed, it is possible that "an undesired outcome is both unintended but also fully foreseen." In fact, some will argue that most of the unintended consequences of drug control policies seem to fall into that category. Most of them have been suspected for decades but keep occurring mostly as the result of the perpetuating, and often of the increase, of inadequate or failed policies and interventions. Such consequences also keep occurring partly because they are often ignored or, to use Merton's terminology, not recognized. Again, most unintended consequences can only be alleged because they are unmeasured and unproven.

But to make things a bit more complex, Helm writes: "An action can perfectly well have unintended consequences which are the effect not of any intended consequences of it but simply of the action itself. So an action may have one or a set of unintended consequences (set I) that is collateral to another consequence or set of consequences (set II), in the sense that set I may have an intended consequence as one of its necessary conditions, set II may not" (Helm, 1971: 52). It is important indeed to acknowledge that the "unintended consequences of intended actions" clearly differ from "the collateral consequences of intended actions" (Helm, 1971: 52).

At this point the understanding of causal mechanisms is essential. Considering how complex interaction effects and contingent conditions can prove and how they can change outcomes in unforeseeable ways, the choice of probabilistic causality over deterministic causality seems logical: one can only assume the likely, not the systematic, effect of an independent variable on a dependent variable. As Friesendorf rightly explains about crop displacement - what he calls a side effect rather than an unintended consequence (8) - the fact that "numerous background conditions, idiosyncrasies, 
and explanatory factors may operate simultaneously or in a random order $[\ldots]$ means that although displacement can be studied as a chronological sequence of events, the underlying causality of displacement cannot be studied in this manner" (Friesendorf, 2005: 44-45). Indeed, illegal drug production and drug control policies and intervention take place in a system of complex interactions that has the potential of generating many unintended and unforeseen consequences. As stressed by Robert Jervis and others, such complex systems are non-linear and cannot be "understood by adding together the units or their relations" (Jervis, 1997; Aoi et al., 2007: 11). Alejandro Portes also expresses skepticism about the routine implementation of a linear relationship, that is, the "straight arrow between the avowed goal of actors-individual or collective-and the achieved end-state" (Portes; 2000: 8) (9).

\section{Direct and collateral unintended consequences (harmful, beneficial, and perverse)}

A typology of unintended consequences is a prerequisite to their study and analysis, if only to avoid a few common mistakes, including an obvious yet not uncommon such mistake mentioned by Chiyuki Aoi et al.: "Unintended consequences need to be distinguished from a failure to achieve the intended consequences" (Aoi et al., 2007: 6). Indeed, an increase in opium poppy cultivation caused by forced eradication clearly differs from a cultivation increase being unhindered by failed forced eradication, or even from a renewed cultivation the year after a successful yet unrepeated forced eradication.

To begin with, one needs to distinguish between two main types of unintended consequences: the unintended consequences of an action (set II of Helm or direct consequences) and the unintended consequences of the intended consequence of the action (set I of Helm or collateral consequences). Direct and collateral unintended consequences can of course be harmful, beneficial, or even neutral (for actors, institutions, and even the environment), but also foreseen or unforeseen. But they can also be perverse.

Perverse unintended consequences are consequences of an action (direct consequence) or of the intended consequence of an action (collateral consequence) that contradict the initial goal of a given purposive action: an increase in cultivation caused by forced eradication or some of its consequences 
(poverty and debt increase) for example. Here the temporal order and the bearers of the action obviously matter: since one consequence may easily become a cause, there are also proximate and ultimate, or rather distal (for causality chains may be endless), unintended consequences that occur very far down and, or, very late, in the causality chain. Indeed, forced eradication can be said to be successful in year 1 but counterproductive in year 2. Perverse unintended consequences obviously should matter the most to policy makers because they reveal the inefficiency or even the counterproductivity of a given policy and, or, intervention.

Yet, as Daase and Friesendorf write, "many unintended consequences do not fall into neat categories": "it is not always clear whether and when unintended consequences impact on policy initiators or others, and whether such consequences are positive or negative" (Daase, Friesendorf, 2010: 10). Still, unintended consequences being consequences that were not planned for in a plan of action, one should distinguish between two main types of unintended consequences: direct and collateral. Such a distinction basically allows us to differentiate the consequences of an action from the consequences of the intended consequence of an action: it can prove useful in assessing the efficiency or the inefficiency of a given policy and of its various interventions.

All public policies create unintended consequences of the direct and collateral types, whether they are beneficial, harmful, neutral, or perverse. Some of them can be foreseen, others cannot. Harms and benefits can be felt at various levels, in the short term or in the long term, and by various bearers: from individuals to various groups and subgroups, governments, nations, to national and international organizations. In the end, drug control policies can only be successful, that is, to achieve their intended consequences, if no perverse unintended consequence is generated or, in other words, if they do not end up being counterproductive. That is, also, when harmful unintended consequences are kept to a minimum so that further consequences, including perverse ones, are less likely (10). 
Table 1. Example of various unintended consequences of forced eradication

\begin{tabular}{|c|c|c|c|c|c|c|c|}
\hline \multicolumn{8}{|c|}{ From action to direct UCs, to intended consequence, and to collateral UCs } \\
\hline & \multicolumn{3}{|c|}{ Direct unintended consequences } & & \multicolumn{3}{|c|}{ Collateral unintended consequences } \\
\hline Action & Beneficial & Harmful & Perverse & $\begin{array}{c}\text { Intended } \\
\text { consequence }\end{array}$ & Beneficial & Harmful & Perverse \\
\hline Eradication & $\begin{array}{l}\text { Restored } \\
\text { law }\end{array}$ & $\begin{array}{l}\text { Violence } \\
\text { increase }\end{array}$ & $\begin{array}{l}\text { "Balloon } \\
\text { effect" }\end{array}$ & $\begin{array}{l}\text { Suppressed } \\
\text { cultivation }\end{array}$ & Price hike & $\begin{array}{l}\text { Poverty } \\
\text { increase }\end{array}$ & $\begin{array}{c}\text { Cultivation } \\
\text { increase }\end{array}$ \\
\hline
\end{tabular}

\section{Unintended consequences of forced eradication}

Drug production reduction can be attempted in three different ways, independently or concurrently: coercion not to plant (when local or national authorities issue and implement a crop ban, out of authority), eradication (when standing crops are destroyed, forcefully or not), and economic development usually referred to as alternative development (when economic alternatives are provided to farmers involved in illegal agricultural production). Forced eradication of drug crops is the most coercive intervention aimed at achieving drug production reduction and provides a good example of the various unintended consequences that drug control policies and their interventions can generate.

The intended consequence of forced eradication (the action) of opium poppies is the suppression of the crop. The most obvious unintended consequences of successful forced eradication are crop displacement and, or, increased cultivation, as mentioned, for example, in a World Bank report on Afghanistan: "A key lesson is that eradication alone will not work and is likely to be counterproductive, resulting in perverse incentives for farmers to grow more drugs (e.g. in Colombia), displacement of production to more remote areas, and fuelling of violence and insecurity (Peru, Bolivia, Colombia), which in several cases forced the eradication policy to be reversed and led to adverse political outcomes" (World Bank, 2004: 87). Here, of course, causality can only be assumed since it can hardly be scientifically proven - on the basis of previous observations (correlations), and also of induction (11). To be more specific, crop displacement and increased cultivation can be said to 
be collateral perverse unintended consequences: the outcome is clearly contrary to the intended consequence of the initial action and is clearly an effect of that intended consequence (set I of Helm). In this case it could be argued that we are also confronted with a foreseen or at least a foreseeable unintended consequence for such consequences have allegedly occurred so often and in so many countries that they could be said to be predictable (12).

Now, the action of forcefully eradicating a crop might also stir armed violence as insurgents (in Afghanistan especially) often oppose the eradication teams (themselves often if not always protected by armed forces). Armed violence can be said to be an unintended consequence of the action itself but not of the crop having being eradicated (that is, the action's intended consequence) per se: it is a direct harmful unintended consequence (set II of Helm) that could easily be foreseen since armed violence often occurs to prevent the action from being carried out and can take place without any eradication being conducted (when violence achieves its goal of preventing eradication).

Environmental pollution and the destruction of food crops or other cash crops can be said to be other direct harmful unintended consequences when eradication is conducted through aerial spraying of chemicals: they can occur outside of the actual destruction of the drug crops and are then consequences not of the drug crop having been destroyed but of the action itself. Here, again, these consequences can easily be foreseen as such collateral damages have often been documented, especially in South America (Messina, Delamater, 2002; Vargas, 2002).

Harmful unintended consequences, whether direct or collateral, are legion and many of them could again easily be foreseen since they have been documented - yet rarely measured or proven - on numerous occasions and in various countries. To name but a few: poverty increase (the main driver of illegal opium production being poverty, eradicating poppy fields most often increases poverty); debt increase (when opium is sold ahead of the harvest and when eradication prevents the repayment of debts); food shortages (when opium is meant to be sold to buy food), school drop-outs (when opium sales allow families to send their children to school), etc. The eradication of an opium poppy crop will often deprive targeted farmers and seasonal workers from most of their income (and, or, ability to repay debts) and resources (access to land, work, credit) and can be said to be responsible of various 
coping strategies (unintended consequences) that include rural exodus, prostitution (especially in Burma), deforestation (as in Burma but also in Afghanistan), poaching (again, in Burma or in Laos), etc. (Chouvy, 2009; Jelsma, Kramer, 2005).

It is important to note that if harmful unintended consequences of forced eradication do not always cause the occurring of perverse unintended consequences, the latter rarely occur outside of preceding harmful unintended consequences: depending on the context and on other factors, poverty and debt increase may or may not lead to crop displacement or increased cultivation. Causality is of course not systematic and some opium farmers may have other options than renew and increase cultivation. Crop displacement is also not systematic and is highly context-dependent and subject to many explanatory factors. What is more, harmful unintended consequences can take place ahead of, or after, perverse unintended consequences: some such consequences (poverty and debt increase for example, but also price hikes) can be caused by the intended consequence (eradicated crops) and be the immediate cause of crop displacement or cultivation increase (to cope with income loss), but other harmful unintended consequences can also be caused by the perverse unintended consequence (deforestation caused by crop displacement, decrease of food crop production caused by increased drug crops) at a later stage. Unfortunately, there are far less beneficial unintended consequences, beyond the price hikes benefiting some farmers, the unlikely development of alternative crops, the even more unlikely lowering of corruption, and targeted poppy cultivators and seasonal workers joining the military (as in Afghanistan).

In the end, forced eradication most often increases poverty and therefore reinforces the main driver of opium production without addressing its causes, including land scarcity, unequal land tenure arrangements, oversized households (Afghanistan) or lack of workforce (Burma, Laos), food insecurity, climatic vagaries, political upheavals, armed conflicts, etc. (Chouvy, 2009; Ducourtieux, 2004; Mansfield, 2004). Forced eradication is highly likely to be counterproductive, that is, to have perverse unintended consequences. Worse, forced eradication also generates many harmful unintended consequences, most of them collateral. We will see that while alternative development also generates harmful unintended consequences, most of them are direct unintended consequences. Also, alternative development is much less likely to provoke perverse unintended consequences. 


\section{Unintended consequences of alternative development}

Rural development, a constructive intervention often labeled as alternative development when implemented in regions of illegal agricultural drug production, sets goals that take much longer to be met and whose success is much more complicated to demonstrate than forced eradication. Causality chains and unintended consequences are far more complex to infer than with forced eradication, not only because development-related interventions have considerably evolved and diversified during the past four decades (unlike forced eradication) but also because rural development being a constructive intervention, it relies on a wide and complex range of actions rather than on single measures. Such actions range from introducing new seeds or new crops, along with improving agricultural techniques and tools, to providing or upgrading health and social equipments and varied infrastructure work. Also, national strategies can be organized around various priority areas and pillars of action. They often involve a large number of actors, from national agencies to international bodies and local and foreign NGOs. Assessing the efficiency of rural development in suppressing or even reducing illegal agricultural drug crops in such complex contexts can obviously prove very difficult.

In fact, many observers agree that "in those places where lasting reductions in production have been seen, other possible influences on farmer decisions not to cultivate drug crops can be put forward as being equally likely causes for change. These include: overall economic growth (Thailand and Viet Nam), political change (Myanmar), increasing government access to formerly remote areas (Pakistan), social pressure (Lao PDR, Bolivia), subsidies (Thailand), and booming prices for alternative crops (coffee and cacao growing areas)" (UNODC, 2005: 9-10; see also Jelsma, 2002).

Unintended consequences of alternative development have also proven very diverse depending on the type of rural development undertaken but also on the extremely varied local settings: the crop substitution programs implemented in Turkey and Thailand in the early 1970s differed from the integrated rural development first experimented with in Peru in the early 1980s, and from the alternative development approach devised in the 1990s and tested for example in Thailand and in Pakistan. Crop substitution programs have been widely documented both in Latin America and in Asia. In the highlands of Thailand such programs produced mixed results in the 1970s with harmful unintended consequences such as market gluts and decreasing prices, soil and stream pollution due to 
excess of chemical pesticides and fertilizers, etc. (Renard, 2001: 57-68) Eventually, the 2000s, marked by the unprecedented increase of Afghanistan's opium production, saw the emergence of the alternative livelihoods approach (13), the last step in a forty-year trend that saw development programs in drug production contexts become increasingly complex (Mansfield, Pain, 2005).

Since the intended consequence of alternative development programs is the reduction or even the suppression of a drug crop, its perverse unintended consequences would presumably be the same compared with forced eradication, that is, crop displacement and, or, increased cultivation. Yet, provided that human security and state stability exist, successful alternative development projects are less likely to have such perverse unintended consequences: alternative development often fails for various reasons but rarely proves counterproductive, unlike forced eradication (Chouvy, 2009). This is actually an example of when "unintended consequences need to be distinguished from a failure to achieve the intended consequences" (Aoi et al., 2007: 6). In the end, alternative development is more likely to provoke direct unintended consequences than collateral unintended consequences. This is because the intended consequence, the suppression of the illegal crop, is rarely obtained (for various reasons), but also because the suppression of an illegal crop is to be obtained by progressively substituting an economy to another one. There is obviously also much less risk of perverse unintended consequences occurring when crop suppression is obtained progressively through economic development than when it is achieved suddenly and without compensation through forced eradication (14). In fact, in the context of alternative development, crop displacement and cultivation increase phenomena are more likely to be the effect not of the intended consequence of the action (alternative development takes years if not decades to achieve drug production reduction) but of the effect of the action itself (the procurement of alternative livelihoods).

Such unintended consequences were suspected in various countries, at various times, and for various reasons, almost always in the short term (Chouvy, 2009: 178-187). In Afghanistan, for example, some alternative development projects are likely to have played a positive role in reducing opium production in targeted areas and for short periods (in Helmand in the late 2000s for example) but are also believed of having quickly spurred production around the project areas. In fact, when rural development projects are scarce and, or, insufficiently funded, opium production can be 
perceived as part of a means of attracting international aid. Alternative development being always carried out locally and often as pilot projects, it can act as an incentive for opium production in areas where no rural development, "alternative" or not, is implemented. Yet the failure of an alternative development project can also lead to the quick resurgence of a drug production, as has been the case in northern Laos in the late 2000s, when poppy cultivation largely resumed because, according to UNODC, of a lack of economic alternatives. The resurgence or even increase of cultivation can also happen despite, and not because of, the implementation of an alternative development project: most notably when alternative development takes place after forced eradication and not before.

\section{Unintended consequences of opium bans}

Opium bans (coercion not to plant) can also prove highly counterproductive, as the opium ban implemented by the Taliban in 2000 clearly showed (Chouvy, 2009: 150-152; Macdonald, 2007: 84). Opium bans differ from eradication for they amount to the interdiction of cultivation, not to the forced destruction of standing crops: local (the Wa in Burma for example) or national authorities (the Taliban, the Pakistani and the Lao governments for example) issue an opium ban and opium farmers comply. Successful interdiction results from the use of authority and power while forced eradication is obtained by force, although threat of force (including eradication) use obviously makes bans more easily and widely respected. A consequence of the Taliban ban was the steep rise of opium prices in the country, which translated into a collateral perverse unintended consequence (15) of the ban (it was a consequence of the intended consequence of the ban), which was that poppy cultivation resumed with renewed vigor as early as 2002 as many opium farmers had to quickly repay their debts (aggravated by the ban) and took advantage of inflated opium prices. These two consequences actually kept driving Afghan opium production up during the following years, in spite of the repeated opium bans pronounced by the Karzai administration.

Such a cultivation and production increase had actually already occurred in Pakistan consecutively to the 1979 Prohibition Order: since the population had been warned in 1978 that opium poppy cultivation would be banned in 1980, the 1979 illegal crop became the largest in Pakistani history, something that was most likely expected and can only be said to have been a direct unintended consequence for it was not an effect of the intended consequence (rather an effect of the 
anticipated intended consequence) but an effect of the action (a forthcoming ban). Here the effective ban was largely held responsible, rightly or not, for a hike of the Afghan production, in the same way that the 2003 surge in cultivation (collateral perverse unintended consequence) in the Wa area of Burma was said to be linked to the opium ban enforced the same year in the neighboring Kokang region. Both the Kokang (2003) and Wa (2005) opium bans also had collateral harmful unintended consequences: assistance was then (and still is) clearly "insufficient to offset the impact of the opium bans, and to cover basic needs of ex-opium farmers" (Transnational Institute, 2005: 16). In fact, according to UNODC, "in Special Region 2 (Wa) [...] where local authorities enforced an opium ban in 2005, farmers have lost up to $70 \%$ of their cash income" (UNODC, 2006: 15).

\section{Of the importance of acknowledging and understanding unintended consequences}

Better assessments of drug control policies and interventions are clearly needed to design policies and interventions that are more efficient, less harmful and, of course, less counterproductive. But a better assessment of drug control policies and interventions requires more than simply enumerating unintended consequences: it actually takes the developing of systematic ways of studying them (Reuter, 2009). And a more thorough study of unintended consequences first requires not confusing them with a failure to achieve the intended consequences (Aoi et al., 2007). Then, as Peter Reuter makes clear, another "important distinction is between consequences that arise from prohibition itself, as opposed to those resulting from specific implementing programmes" (Reuter, 2009: 2010).

What is also required is discerning between the two main types of unintended consequences: direct and collateral, that is, between, the unintended consequences of an action and the unintended consequences of the intended consequence of an action (Helm, 1971). Differentiating between direct and collateral unintended consequences makes a more precise assessment of actions and of their intended consequences possible. Since the reduction or suppression of illegal drug cultivation can be obtained through three different interventions, separately or concurrently, in various sequencing orders, and with different resources made available for each intervention, a better assessment of drug supply reduction at the production level implies analyzing complex interaction effects and contingent conditions that can change outcomes in unforeseeable ways. As stressed by Friesendorf, empirical black boxes, complex and dynamic interaction effects, corruption, and the "difficulty of assigning 
causal weight to explanatory factors and processes" makes the study of unintended consequences a very difficult undertaking (Friesendorf, 2005: 67). Yet, differentiating between direct and collateral unintended consequences allows us to better attribute the occurring of unintended consequences to a specific intervention or to a specific set of interventions, on the one hand, and to the intended consequence of the interventions on the other hand.

Harmful unintended consequences are of course to be avoided as much as possible, whether they occur before or after the suppression of illegal drug cultivation, in the short term or in the long term, and no matter who the bearers are. Cost-benefit analyses obviously matter to assess whether the value of the intended consequences outweighs the harms associated with the unintended consequences but drug control policies and interventions can still be successful despite causing serious harms to various bearers. Yet, harmful unintended consequences can foster perverse unintended consequence and compromise drug control policies altogether. Avoiding perverse unintended consequences, i.e. the counterproductivity of the actions undertaken or of their intended consequences, is of course a prerequisite to more efficient drug control policies. The fact that collateral perverse unintended consequences are much less likely to be generated by alternative development than by forced eradication shows that it is the interventions and not their basically identical intended consequences (the reduction and, or, suppression of illegal drug cultivation) that are to be better selected to achieve drug control policy goals.

Specifying expected outcomes of drug control policies, on one hand, and, on the other hand, acknowledging errors from the past in order to avoid perverse but also harmful unintended consequences - and especially the foreseeable ones - is key to a more efficient and less detrimental international drug control regime. The variety and complexity of unintended consequences clearly needs to be integrated in the design process of drug control policies in order to avoid counterproductive drug control interventions. Yet, at this stage, further theoretical and empirical work is obviously needed to better understand how and why intended and unintended consequences of drug control policies and interventions are produced. What is needed is more complex and detailed typologies along with more accurate descriptions of the causality chains at work, something that 
obviously requires specific empirical research, for example on where, when, how, and why cultivation increases and crop displacements occur, or not.

\section{Notes}

1) This article is part of the LINKSCH Research Project, funded by the European Commission. Thanks go to Laurent Laniel and David Mansfield for their comments on earlier drafts of this paper.

2) Geographer and research fellow at CNRS-Prodig, Paris, France. Author of Les territoires de l'opium (2002, Genève: Olizane), Yaa Baa (2004, Singapore: Singapore University Press), and Opium. Uncovering the Politics of the Poppy (2009 / 2010, London / Cambridge: I.B. Tauris / Harvard University Press).

3) Allegedly 1,066 tons in 1970 , one year before the launch of the war on drugs, and, according to the United Nations Office on Drugs and Crime, at least 10,649 tons in 2009, including 2,895 tons of non-processed opium (UNODC, 2010). In 2012, without explanation, UNODC did not mention (or did not include in its estimate?) any production of nonprocessed opium, making its global estimate of 6,995 tons impossible to compare with the 2009 output (UNODC, 2012).

4) Despite the post-1971 surge in illegal production of opium, coca, and maybe cannabis, partisans of the containment theory suggest that an "increase in the size and scope of the illicit drug industry would have been far greater in the absence of law enforcement" (Windle and Farrel, 2012: 874). Others adopt a more balanced approach: "The consolidation and expansion of the control regime in the 1960s, 1970s, and 1980s, to include prohibition against consumption, did not prevent renewed expansion of opiate consumption or the tendency toward mass markets and widespread distribution networks-nor does the adoption of the more stringent policies appear to have caused them" (Paoli, Greenfield, Reuter, 2012: 932).

5) On the difference between typology and taxonomy, see Smith, 2002. 
6) Understanding Society, blog of Daniel Little:

http://understandingsociety.blogspot.fr/search?q=unintended+consequences (retrieved on 14 May 2012).

7) Although Merton refers to unintended and unanticipated consequences of actions interchangeably in a footnote of his 1957 book Social Theory and Social Structure

8) In another text, Friesendorf, along with Christopher Daase, explains that it is better to speak of unintended consequences rather than of side effects or paradoxical effects: referring to Jervis they ask how one can say which effect was a main effect and which one was a side effect. (Daase, Friesendorf, 2010: 9)

9) Portes actually offers a valuable typology of five alternatives that represent different end-states from those assumed by a purposive logic: (1) the real goal is not the apparent one; (2) the real goal is not what the actors actually achieve; (3) the real goal emerges from the situation itself; (4) the original goal is real, but the end-state is contrary to its intent; (5) the original goal is real, but it is achieved by an unexpected combination of events (Portes, 2000: $8)$.

10) It was asked by two anonymous reviewers of this paper to refer to the literature on types of crime displacement (Repetto, 1976) and on the diffusion of benefits theory, according to which the geographical displacement of crime (crimes prevented in a given area are displaced into other areas), for example, happens along with the geographical diffusion of benefits (in addition to crime reduction or suppression in the target area there are further benefits in terms of reduced crime levels in other areas) (Barr and Pease, 1990 ; Clarke and Weisburd, 1994). Yet we doubt that an approach in terms of crime displacement and of diffusion is adapted to the subject under review, for various reasons: because opium farmers are not criminals (maybe offenders, but not by choice); because opium production is more an economic matter than a police or military matter; because crop displacement in rural areas of poor countries cannot decently be compared to crime displacement in cities of modern countries; and because the diffusion of benefits is very unlikely to take place in the case of forced eradication (low opportunity cost of planting opium poppy and having it eradicated, 
which means that cultivating wheat instead of opium poppy is generally not an option as few farmers have sufficient land) or in the case of alternative development (the history of AD is mostly a history of failed small scale projects and no so-called halo, bonus, free-rider or other multiplier effects can be envisaged).

11) David Hume explains how induction - and not reasoning - allows us to link these two propositions: "I have found that such an object has always been attended with such an effect, and Iforesee, that other objects, which are, in appearance, similar, will be attended with similar effects". Hume then explains: "I shall allow, if you please, that the one proposition may justly be inferred from the other: I know, in fact, that it always is inferred. But if you insist that the inference is made by a chain of reasoning, I desire you to produce that reasoning.” (Hume, 1902 (1748): part II §29)

12) Francisco Linares distinguishes weak from strong unintended consequences:

"Unintended consequences which are foreseeable (whether desirable or undesirable) are not "unexpected" in the same sense that unforeseeable ones are (that is why they are "weak"), because the causal mechanism in the second case is not usually clear" (Linares, 2009: 8).

13) The alternative livelihoods approach has emerged in order to overcome the limitation of previous development approaches that have been "designed as a specific response to reductions in opium production" but did not address "the underlying structural and institutional reasons that have led to the growth of opium poppy cultivation in the first place" (Mansfield, 2007: 70).

14) The speed of implementation that characterizes forced eradication actually explains, in part, its non durability.

15) The rumor actually went that such an outcome was actually intended or at least that the Taliban planned on benefiting from the sale of opium stocks at increased prices. 


\section{Bibliography}

Aoi, C., et al. (2007). Unintended Consequences of Peacebuilding Operations. Tokyo - New York Paris: United Nations University Press.

Baert, P. (1991). Unintended consequences: a typology and examples. International Sociology. Vol. 6, pp. 201-210.

Barr, R., \& Pease, K. (1990). Crime Placement, Displacement, and Deflection. In M. Tonry and N. Morris (eds.), Crime and Justice: A Review of Research, Vol. 12, pp. 277-318, Chicago: University of Chicago Press.

Bertram, E., Blackman, M., Sharpe, K., \& Andreas, P. (1996). Drug War Politics: The Price of Denial. Berkeley: University of California Press.

Boudon, R. (1982). The unintended consequences of social action. London: Macmillan Press.

Chouvy, P.-A. (2009). Opium. Uncovering the Politics of the Poppy. London: I.B. Tauris.

Clarke, R.V. \& Weisburd, D. (1994). Diffusion of Crime Control Benefits: Observations on the Reverse of Displacement. In R.V. Clarke (ed.), Crime Prevention Studies, Vol. 2, pp. 165-182, Boulder: Lynne Rienner Publishers.

Costa, A. M. (2008). Making drug control 'fit for purpose': Building on the UNGASS decade. Statement of the Executive Director of the United Nations Office on Drugs and Crime, Fiftyfirst session of the Commission on Narcotic Drugs, Vienna, 10-14 March 2008.

Daase, C., \& Friesendorf, C. (2010). Rethinking Security Governance: The Problem of Unintended Consequences. London - New York: Routledge.

Ducourtieux, O. (2004). Shifting Cultivation and Poverty Reduction in the Uplands of Lao PDR: A Complex Issue. Proceedings from NAFRI Uplands Workshop on Shifting Cultivation Stabilization and Poverty Eradication. Luang Prabang, pp. 71-94.

Elster, J. (1978). Logic and society. Contradictions and possible worlds. London: John Wiley \& Sons. 
Friesendorf, C. (2005). Squeezing the balloon? United States Air Interdiction and the Restructuring of the South American Drug Industry in the 1990s. Crime, Law \& Social Change. Vol. 44, pp. $35-$ 78.

Friesendorf, C. (2007). US Foreign Policy and the War on Drugs: Displacing the Cocaine and Heroin Industry. London - New York: Routledge.

Heckman, J. T. (2005). The Scientific Model of Causality. Sociological Methodology. Vol. 35, pp. 197.

Heilmann, D. P. P. (2010). The international control of illegal drugs and the U.N. treaty regime: Preventing or causing human rights violations? SelectedWorks, Berkeley Electronic Press.

Helm, P. (1971). Manifest and Latent Functions. The Philosophical Quarterly. 21:82, pp. 51-60.

Holland, P. W. (1986). Statistics and Causal Inference. Journal of the American Statistical Association. 81:396, pp. 945-960.

Hume, D. (1902) (1748). Enquiries Concerning the Human Understanding, and Concerning the Principles of Morals. Retrieved on 6 May 2012 from http://www.gutenberg.org/files/9662/9662h/9662-h.htm.

Jervis, R. (1997). System Effects: Complexity in Political and Social Life. Princeton, NJ: Princeton University Press.

Jelsma, M. (2002). “Alternative Development And Drug Control: A Critical Assessment”, Keynote speech, International Conference on The Role of Alternative Development in Drug Control and Development Cooperation, Feldafing, Germany, 8 January 2002.

Jelsma, M., \& Kramer T. (2005). Downward Spiral. Banning Opium in Afghanistan and Burma. Drugs \& Conflict Debate Papers $N^{\circ} 12$. Amsterdam: Transnational Institute.

Linares, F. (2009). Weak and Strong Unintended Consequences: Agent's Rationality and Predictability of Outcomes in Systems of Action. The Open Sociology Journal. Vol. 2, pp. 1-9.

Macdonald, D. (200). Drugs in Afghanistan. Opium, Outlaws and Scorpion Tales. London - Ann Arbor: Pluto Press. 
Mansfield, D. (2004). Diversity and Dilemma: Understanding Rural Livelihoods and Addressing the Causes of Opium Poppy Cultivation in Nangarhar and Laghman, Eastern Afghanistan. A Report for the Project for Alternative Livelihoods (PAL) in Eastern Afghanistan, Internal Document $n^{\circ} 2$, GTZ.

Mansfield, D. (2007). Responding to the challenge of diversity in opium poppy cultivation in Afghanistan. In D. Buddenberg, W. Byrd (Ed), Afghanistan's Drugs Industry: Structure, functioning, dynamics and implications for counter narcotics policy. Kabul: UNODC/World Bank, pp. 47-76 (draft version).

Mansfield, D., \& Pain, A. (2005). Alternative Livelihoods: Substance or Slogan? AREU Briefing Paper, October 2005, Kabul: Afghanistan Research and Evaluation Unit.

Merton, R.K. (1936). The Unanticipated Consequences of Purposive Social Action. American Sociological Review, 1:6, pp. 894-904.

Merton, R.K. (1957). Social Theory and Social Structure. Glencoe: The Free Press.

Messina, J.P., \& Delamater, P.L. (2002). Defoliation and the war on drugs in Putumayo, Colombia. International Journal of Remote Sensing, 27:1, pp. 121-128.

Nadelmann, E. A. (1988). U. S. Drug Policy: A Bad Export. Foreign Policy, No 70, pp. 83-108.

Nadelmann, E. A. (2010). My Testimony to Congress on the War on Drugs. Huffington Post. Retrieved on 12 June 2012 from http://www.huffingtonpost.com/ethan-nadelmann/mytestimony-to-congress_b_537915.html.

Paoli, L., Greenfield V., \& Reuter, P. (2012). Change is Possible: The History of the International Drug Control Regime and Implications for Future Policymaking. Substance Use and Misuse, 47:8-9, pp. 923-935.

Portes, A. (2000). The hidden abode: sociology as analysis of the unexpected. American Sociological Review. Vol. 65, pp. 1-18. 
Renard, R. D. (2001). Opium Reduction in Thailand 1970-2000. A Thirty-Year Journey. Bangkok: UNDCP - Silkworm Books.

Repetto, T.A. (1976) Crime Prevention and the Displacement Phenomenon. Crime and Delinquency. Vol. 22, pp.166-177.

Reuter, P. (2009). The unintended consequences of drug policies. Santa Monica: Rand Corporation.

Reuter, P., \& Greenfield, V. (2001). Measuring Global Drug Markets. How good are the numbers and why should we care about them? World Economics, 2:2, pp. 159-173.

Smith, K.B. (2002). Typologies, Taxonomies, and the Benefits of Policy Classification. Policy Studies Journal, 30:3, pp. 379-395.

Thoumi, F. (2005). The Numbers Game: Let's All Guess the Size of the Illicit Drug Industry! Journal of Drug Issues, 35:1, pp. 185-200.

Transnational Institute. (2005). Downward Spiral. Banning Opium in Afghanistan and Burma. Drugs and Conflicts, Debate Papers n ${ }^{\circ}$ 12, Amsterdam: TNI.

Tullis, L. (1995). Unintended Consequences. Illegal Drugs and Drug Policies in Nine Countries. Boulder: Lynne Rienner.

UNODC. (2005). Thematic Evaluation of UNODC Alternative Development Initiatives, Independent Evaluation Unit, Draft version, 4 September 2005.

UNODC. (2006). Opium Poppy Cultivation in the Golden Triangle. Lao PDR, Myanmar, Thailand. Bangkok: United Nations.

UNODC. (2010). World Drug Report 2010. Vienna: UNODC.

UNODC (2012). World Drug Report 2012. Vienna: UNODC.

Vargas, R. (2002). The Anti-Drug Policy, Aerial Spraying of Illicit Crops and their Social, Environmental and Political Impacts in Colombia. Journal of Drug Issues, 32:1, pp. 11-60. 
Windle, J., \& Farrell, G. (2012). Popping the Balloon Effect: Assessing Drug Law Enforcement in Terms of Displacement, Diffusion, and the Containment Hypothesis. Substance Use and Misuse, 47:8-9, pp. 868-876.

World Bank. (2004). Afghanistan. State Building, Sustaining Growth, and Reducing Poverty. Washington, D.C.: The World Bank. 